\title{
NASA GRC Compass Team Conceptual Point Design and Trades of a Hybrid Solar Electric Propulsion (SEP)/ Chemical Propulsion Human Mars Deep Space Transport (DST) Vehicle
}

\author{
Melissa L. McGuire, ${ }^{1}$ Steven R. Oleson, ${ }^{2}$ Laura M. Burke ${ }^{3}$, \\ J. Michael Newman, ${ }^{4}$ and Michael C. Martini ${ }^{5}$ \\ NASA Glenn Research Center, Cleveland, Ohio, 44135, USA
}

\begin{abstract}
NASA has long been conducting studies which apply different in-space propulsion technology assumptions to the mission of sending humans to Mars. Two of the technologies under study that are considered to be the most near-term with respect to technology readiness level (TRL) are traditional chemical propulsion systems and high-power Solar Electric Propulsion (SEP) systems. The benefit of relatively low trip times inherent in using impulsive chemical propulsion systems to perform the full round-trip $\Delta V$ for human Mars missions is hampered by the large propellant mass required to perform these burns. SEP systems offer the benefit of much lower propellant requirements to perform the same round-trip missions, at the cost of longer trip times. Traditionally, impulsive chemical systems are better suited than SEP when used in a gravity well, and SEP systems are more efficient than traditional impulsive systems when used in interplanetary space. A typical mission to Mars includes both of these scenarios, and thus several NASA architecture studies, performed over the last few years, have looked to combine the use of both SEP and chemical propulsion systems where they are the most beneficial to human Mars missions. This combined propulsion system concept has been referred to as a SEP/Chem hybrid Mars Transfer Vehicle and is currently shown as the concept Deep Space Transport (DST) in the March 2017 NASA presentation to the National Aerospace Council (NAC).
\end{abstract}

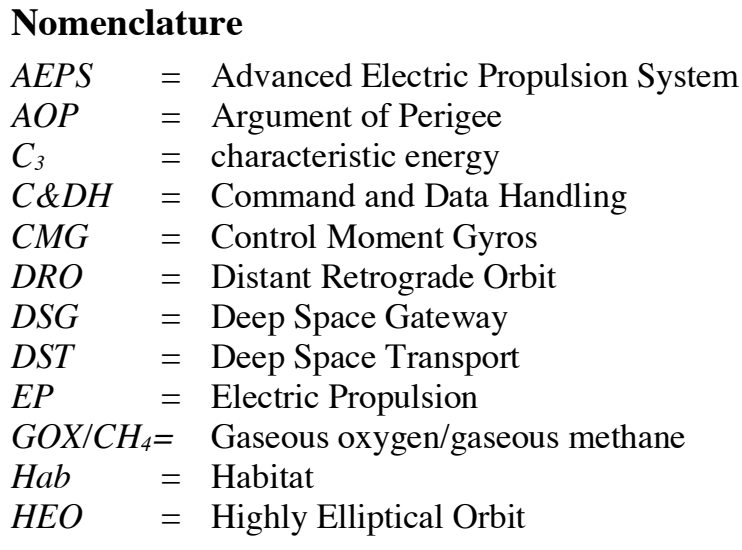

\footnotetext{
${ }^{1}$ Branch Chief, Mission Architecture and Analysis Branch, NASA Glenn Research Center.

${ }^{2}$ Compass Team Lead, Mission Architecture and Analysis Branch, NASA Glenn Research Center. AIAA Senior Member Grade

${ }^{3}$ Mission Design Engineer, Mission Architecture and Analysis Branch, NASA Glenn Research Center.

${ }^{4}$ Compass Team Systems Integration Lead, Mission Architecture and Analysis Branch, NASA Glenn Research Center.

${ }^{5}$ Mission Design Engineer, Mission Architecture and Analysis Branch, NASA Glenn Research Center. AIAA Senior Member
} 


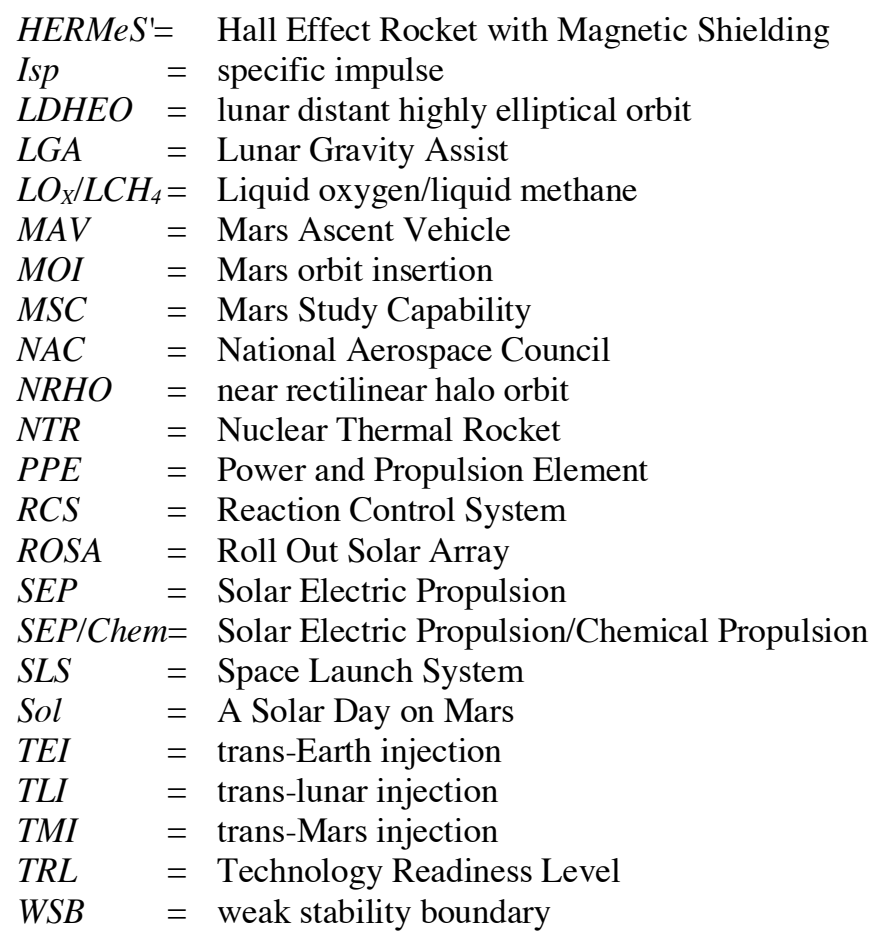

\section{I.Introduction}

NASA Glenn Research Center's concurrent engineering design team, Compass, has performed several concept designs of a Solar Electric Propulsion (SEP)/Chem Hybrid Human Mars Transfer Vehicle, capable of safely sending a crew of four to Mars and returning them home to Earth. Also referred to as the Deep Space Transport (DST) [1] in the current NASA preliminary exploration concepts, the design documented here was performed for NASA's Mars Study Capability (MSC) team and built upon previous Compass concept designs of this type of Human Mars Transfer Vehicle[2]. Combining SEP and Chemical Propulsion in the Human Mars Transfer Vehicle takes advantage of the strengths of both propulsion systems to efficiently and robustly send humans to and from Mars. For Mars opportunities starting in 2033, and extending through to 2045, this SEP/Chem hybrid vehicle, also referred to as DST, would be outfitted and refueled in a lunar near rectilinear halo orbit (NRHO) and be capable of delivering a pressurized Habitat with a crew of four to an orbit about Mars. Launched with only enough fuel to deliver itself to the NRHO on a single Space Launch System (SLS) rocket to a trans-lunar injection (TLI) trajectory, the SEP/Chem hybrid Mars Transfer Vehicle would transfer to NRHO and meet with NASA's Deep Space Gateway (DSG) or with another element to refuel (xenon and chemical propellant) and resupply logistics and supplies for the Habitat.

The Compass Team's design study provides a detailed conceptual point design (pre-phase A level) against which trades can be made to ascertain the impact of different subsystem technologies. This paper captures the concept design. It also captured the system level benefits and impacts of technology development of the Chemical and Electric Propulsion (EP) systems on a human Mars mission. Figure 1 is an artist's depiction of the hybrid SEP/Chem propulsive DST vehicle. This baseline vehicle used $\mathrm{LO}_{\mathrm{X}} / \mathrm{LCH}_{4}$ as the primary chemical propulsion system and $13.3 \mathrm{~kW}$ Hall Effect thruster strings, currently under development for the Advanced Electric Propulsion System (AEPS) contract. These thrusters are also planned as the primary EP system for the Power and Propulsion Element (PPE) of NASA's Gateway as the primary EP system. In order to fully understand the impact of propulsion system technologies on the round-trip mission, an optimized end-to-end trajectory was developed for the baseline design, as well as for each of the propulsion system trade cases.

\section{II.Concept of Operations}

The following notional concept of operations for the DST (illustrated in Figure 2) was used to create a baseline design referred to throughout this paper as Case 1, and was applied consistently to all of the trade cases. The DST was assumed to be a single integrated vehicle, composed of a pressurized crew Habitat and a power and propulsion 
Transport module. The DST was assumed to be launched on a single SLS and delivered to an orbit about the Earth. In order to fit inside a single SLS (Item 1 in Figure 2), it was assumed that the DST would be launched with propellant sufficient to deliver itself to the NRHO and would then require refueling to complete the round-trip Earth to Mars mission (Item 2 in Figure 2). The number of resupply/refueling vehicles and their designs were left for future design studies. Once the DST was fueled and outfitted (Item 4 in Figure 2), it would transfer to a lunar distance high Earth orbit (LDHEO) where it would rendezvous with the crew that was launched in the Orion by way of an SLS to the same LDHEO. After the crew transferred over to the DST (Item 5 in Figure 2), the Orion would separate and return to Earth. The DST would perform a series of lunar gravity assist (LGA) maneuvers, followed by a chemical transMars injection (TMI) burn to achieve its escape from Earth. From there the DST would continue with the rest of the interplanetary

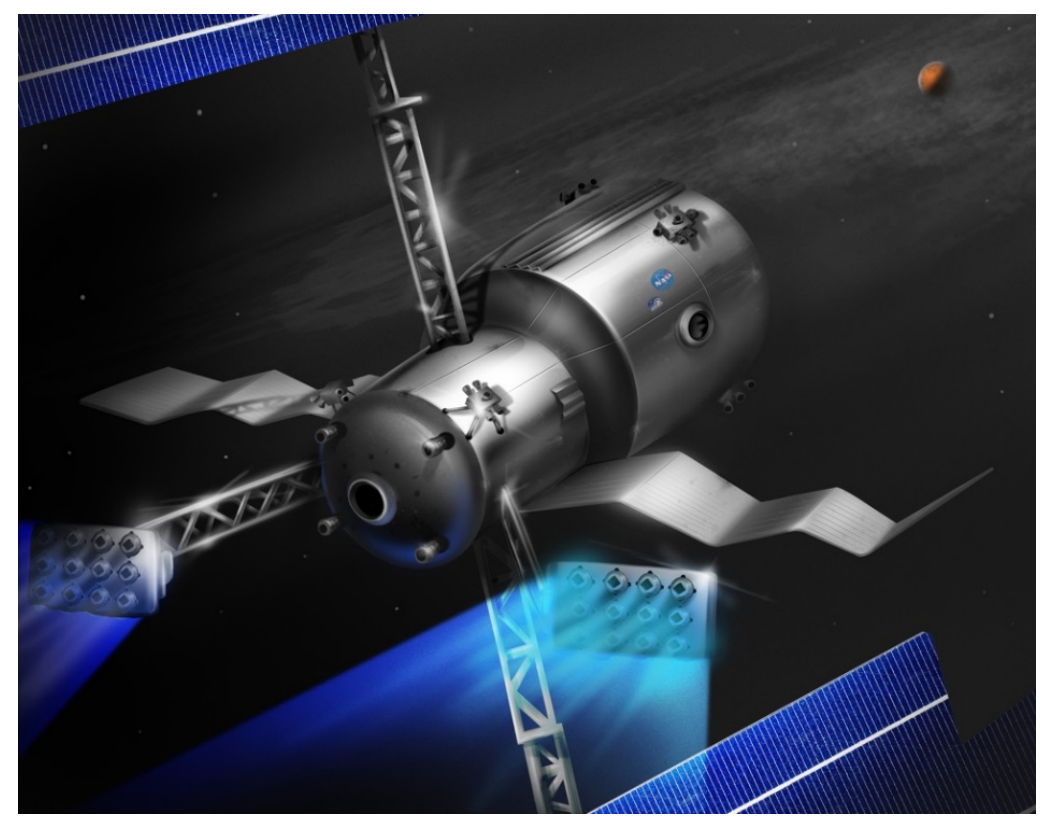

Figure 1: Artist depiction of the Deep Space Transport (DST) Crew vehicle.

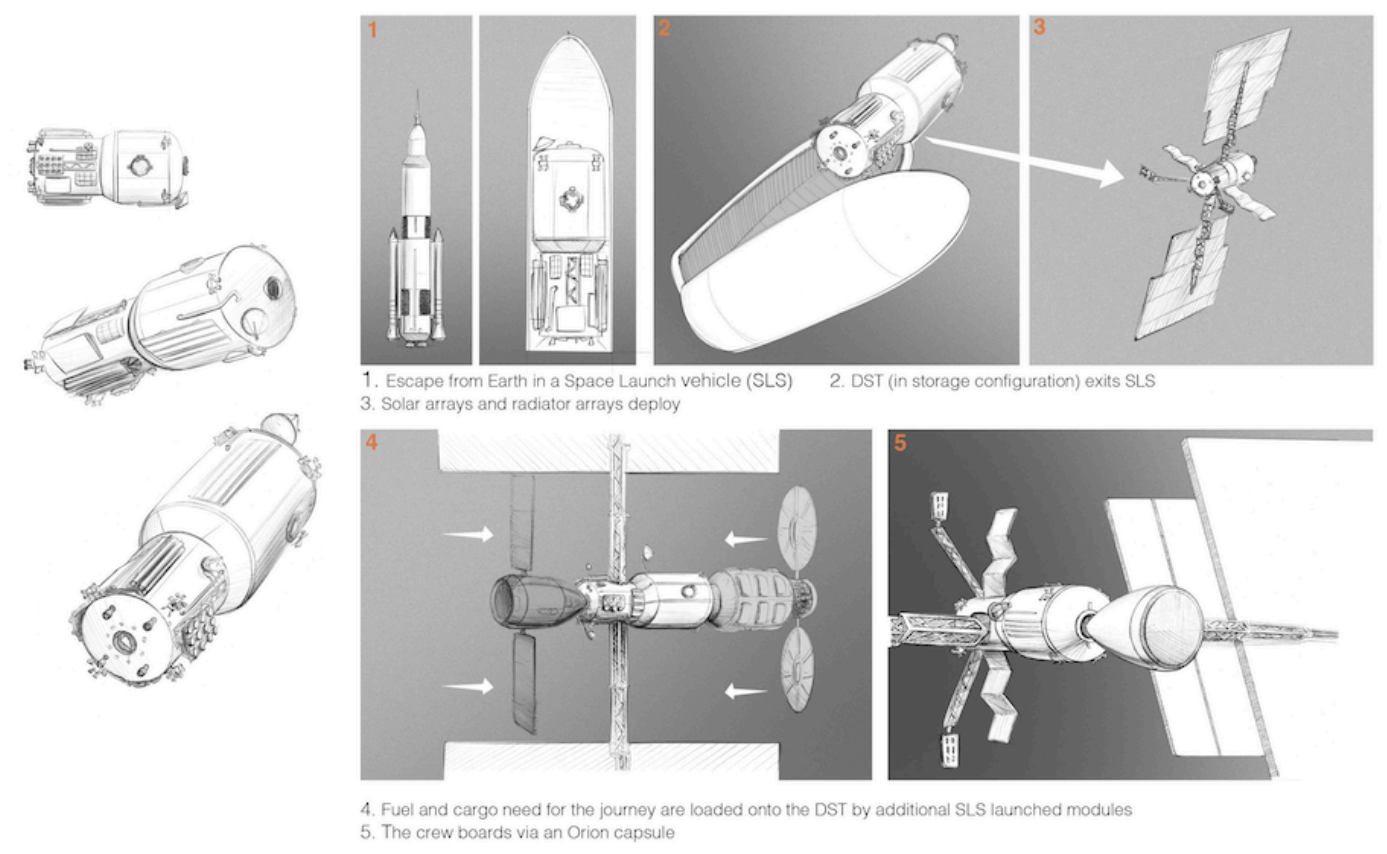

Figure 2: Notional Artist Interpretation of DST Assembly Sequence 
cruise phase utilizing the SEP system. At Mars, the DST would capture into a 5 Sol orbit using the chemical thrusters to perform the Mars orbit insertion (MOI) burn. Next, the crew would utilize a pre-deployed taxi at Mars to move from the DST to taxis which deliver them to orbiting, pre-deployed Mars landers. After spending $\sim 300$ days on the surface, the crew would return to the orbiting DST using the pre-deployed Mars Ascent Vehicle (MAV). Once returned to the DST, a trans-Earth injection (TEI) burn is performed using the chemical thrusters to escape Mars, followed by SEP thrusting in interplanetary space. Upon returning to Earth, the DST would perform a sequence of LGA maneuvers to capture back into the LDHEO. Once in the LDHEO, the DST would rendezvous with the Orion which would then separate and return the crew to Earth. Using a weak stability boundary (WSB) transfer, the DST would return to the original NRHO for refueling and refitting for the next human Mars mission opportunity.

\section{Mission Description}

Trajectory analysis and optimization of human Mars missions has been explored by many mission designers throughout the years. [3], [4], [5], [6] Both low thrust (e.g., electric propulsion systems) [7], [8] and high thrust (chemical, nuclear thermal rocket (NTR), etc.) propulsion options have been examined. [9] Recent analysis has focused on applying both low and high thrust propulsion systems together on a single vehicle and utilizing each type where they work best in a round-trip Mars mission. [10] Low thrust systems work best outside of the gravity wells and can more efficiently use propellant to provide $\Delta \mathrm{V}$ at the cost of longer trip times. High thrust systems are well suited for use in escaping and capturing into gravity wells at the cost of higher propellant usage. In 2013 the Compass Team explored the application of a combined SEP/Chem system to the design of a crewed vehicle to fly NASA's DRM 5.0 mission. [11],[12] The DST concept documented in this paper was built upon these previous analyses, and designed to combine the best of low thrust and high thrust propulsion systems for round-trip delivery of a crew of four from the Earth to Mars.

\section{A. Baseline Reference Trajectory}

In March of 2017, NASA announced its conceptual next steps for exploration of destinations beyond LEO. The first phase of this exploration will involve building a Gateway in orbit about the Moon. [13] The reference trajectory used for the baseline DST design in this paper was a 2037 Mars opportunity crewed surface mission to Jezero Crater (see Figure 3). The DST was assumed to dock to the Gateway in a 9:2 near rectilinear halo orbit (NRHO) [14] during initial outfitting and for refit and refueling following completed missions. For crewed missions, it was assumed that the SEP-Hybrid vehicle performs a 6 month near-ballistic WSB transfer from the NRHO to a lunar distant highly elliptical orbit (LDHEO) to await rendezvous with the crew. During uncrewed periods in the LDHEO the SEP-Hybrid must perform $10 \mathrm{~m} / \mathrm{s}$ orbit maintenance burns during each orbit to maintain perigee altitude. Where possible, the trajectory was modeled such that the EP system would perform the $\Delta$ V's due its more efficient higher Isp (Specific Impulse) system.

Following crew rendezvous in the LDHEO, the DST may require up to three additional orbits to achieve the correct phasing necessary to perform a LGA maneuver sequence to increase the outgoing $\mathrm{C}_{3}$ to $2 \mathrm{~km}^{2} / \mathrm{s}^{2}$. In this analysis, the DST escapes Earth on July 18, 2037. The SEP system is used during the outbound interplanetary transit to reduce the departure and capture chemical propulsion burns done near Earth and Mars. Because the EP system cannot provide sufficient initial acceleration following the LGAs to reach Mars while enabling a 300-day surface stay, the chemical system must perform a $360 \mathrm{~m} / \mathrm{s}$ TMI burn.

The crewed vehicle arrives at Mars on August 7, 2038 and uses the chemical propulsion system to perform a $138 \mathrm{~m} / \mathrm{s}$ MOI burn to capture into the desired $5 \mathrm{Sol}$ orbit. To enable landing near the Jezero Crater, the argument of perigee (AOP) of the arrival orbit is constrained to be equal to the latitude of Jezero Crater, $18.8^{\circ}$. During Mars stay, the DST uses the SEP propulsion system to complete an $11 \mathrm{~m} / \mathrm{s}$ reorientation maneuver to align the departure orbit. The inclination of the departure orbit is constrained to be greater than or equal to $18.8^{\circ}$ to enable the MAV to perform a coplanar launch and rendezvous. After the crew transfers back to the DST in the departure orbit, the DST chemical propulsion system performs a $220 \mathrm{~m} / \mathrm{s}$ TEI burn to escape Mars.

The SEP system is used during the Earth inbound interplanetary transit to reduce the departure burn done near Mars and to ensure that the arrival $C_{3}$ at Earth remains under $2 \mathrm{~km}^{2} / \mathrm{s}^{2}$. This arrival velocity requirement facilitates the capture back into the LDHEO following another LGA maneuver sequence. Orion will again rendezvous with the SEPHybrid DST vehicle in order to deliver the crew back safely to Earth. Following Orion separation, the DST will transfer back to the NRHO via WSB transfer to dock with Gateway to prepare for its next mission.

The trajectories documented in this paper are modeled using the high-fidelity trajectory tool, Copernicus. Copernicus development started at the University of Texas at Austin and currently continues at Johnson Space Center (JSC). [15] Copernicus is a generalized spacecraft trajectory design and optimization tool, capable of designing low 
thrust and impulsive trajectories. [16] Copernicus is an n-body tool and is considered high fidelity. The solutions presented in this paper are from fully integrated trajectories using both impulsive and finite burns to model the chemical and EP propulsion systems. The DE430 ephemeris model was used with point masses for the Earth and Moon. Solar radiation pressure has not been modeled at this time.

\section{B. Mission Mass Summary}

In order to accurately model the round-trip trajectory, all mass drop/add assumptions, both from propulsion system operations and the assembly on orbit, needed to be tracked. A summary of all the mass and $\Delta \mathrm{V}$ assumptions provided by MSC for the study is seen in Table 1. The waste mass drops are functions of mission duration and consumption rate and occur at several points in the mission. Where possible, it was assumed that the EP system would perform the $\Delta \mathrm{V}$ 's due to its significantly greater efficiency compared to the chemical system.

A mission chronological accounting of all mission $\Delta \mathrm{V}$ 's, along with propellant consumption and mass drops can be seen in Table 2. All propellant numbers in Table 2 represent usable propellant. Margin was carried on all propellants; An additional 5\% of usable xenon, $5 \%$ of useable main chemical propellant, and $10 \%$ of usable RCS/ACS propellant, and is included in the vehicle inert mass summary.

\begin{tabular}{|c|c|}
\hline \multicolumn{2}{|c|}{ Case 1 - AEPS Thrusters, LOX/LCH4 } \\
\hline Earth Escape Date & July 18,2037 \\
\hline Earth Arrival Date & May 19, 2040 \\
\hline Outbound TOF (days) & 385 \\
\hline Mars Stay Time (days) & 300 \\
\hline Inbound TOF (days) & 351 \\
\hline \multicolumn{2}{|l|}{ Effective EP $\Delta V \mathrm{~s}(\mathrm{~m} / \mathrm{s})$} \\
\hline Outbound SEP DV - Earth Departure (2666s) & 2156.0 \\
\hline Outbound SEP DV - Earth Departure (2666s) & 1040.2 \\
\hline Re-orientation SEP DV (2666s) & 11.4 \\
\hline Inbound SEP DV - Mars Departure (2666s) & 2447.9 \\
\hline Inbound SEP DV - Earth Slowdown (2666s) & 608.5 \\
\hline \multicolumn{2}{|l|}{ Chemical $\Delta V_{s}(\mathrm{~m} / \mathrm{s})$} \\
\hline TMI DV (351s) & 360.2 \\
\hline MOI DV (351s) & 137.8 \\
\hline On-Orbit Station-keeping (351s) & 20.0 \\
\hline TEI DV (351s) & 219.9 \\
\hline Mass at Earth Return (t) & 63 \\
\hline
\end{tabular}

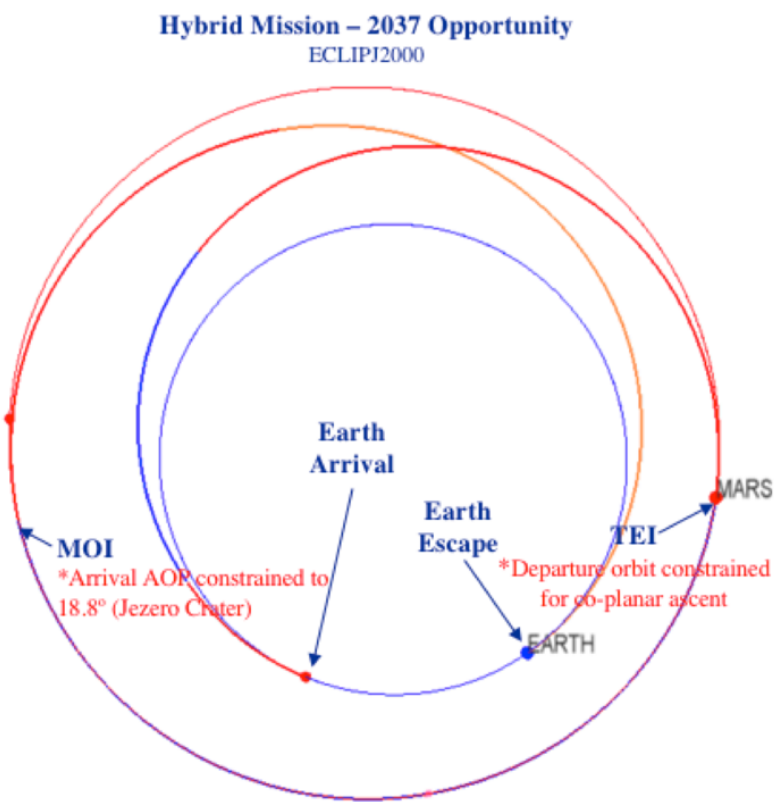

24x 13.3kW Hermes Thrusters $\begin{aligned} & \text { 二 COAST } \\ & \text { BURN }\end{aligned}$

Figure 3: 2037 Interplanetary Reference Trajectory for the Compass Design of the Deep Space Transport (DST)

Table 1: Mass and $\Delta \mathrm{V}$ Assumptions

\begin{tabular}{lccc}
\hline \hline Parameter & $\begin{array}{c}\text { Value } \\
(\mathbf{k g})\end{array}$ & $\begin{array}{c}\text { Parameter } \\
\text { Masses }\end{array}$ & $\begin{array}{c}\text { Delta V } \\
(\mathbf{m} / \mathbf{s})\end{array}$ \\
$\quad 21,090$ & TLI Cleanup, Target LGA \\
Orion & 328 & Insert into NRHO via WSB \\
Crew & 14,040 & Dock to Gateway in NRHO \\
Logistics Loaded at Gateway & 1896 & Depart LDHEO from NRHO via WBS \\
Items offloaded of Hab, loaded at Gateway & 4300 & Burn to eliminate Lunar Resonance \\
Logistics Module Inert Mass & 8700 & Station Keeping in LDHEO/Rev \\
Logistics Module Payload & 250 & Phasing burn, depart LDHEO, target WSB \\
Samples Obtained from Martian Surface & & 5 Sol Parking Orbit Maintenance at Mars \\
Waste Mass Drops & 2325 & \\
$\quad$ Prior to MOI & 4896 & \\
$\quad$ Prior to TEI & 2125 & \\
Prior to Earth Arrival & & \\
\hline \hline
\end{tabular}


Table 2: Mission $\Delta \mathrm{V}$ and Propellant Summary

\begin{tabular}{|c|c|c|c|c|c|c|c|c|c|c|c|c|}
\hline \multicolumn{13}{|c|}{ Mission DeltaV Summary } \\
\hline \multirow[t]{2}{*}{$\begin{array}{c}\text { Phase } \\
\#\end{array}$} & \multirow[t]{2}{*}{ Phase Name } & \begin{tabular}{|c|} 
Pre-Burn \\
Mass
\end{tabular} & EP DV & $\begin{array}{l}\text { Main } \\
\text { Chem } \\
\text { DV }\end{array}$ & $\begin{array}{c}\text { RCSI } \\
\text { ACS } \\
\text { DV } \\
\end{array}$ & $\begin{array}{c}\text { Main } \\
\text { Isp }\end{array}$ & \begin{tabular}{|l|} 
RCSI \\
ACS \\
Isp \\
\end{tabular} & EP Prop & $\begin{array}{l}\text { Main } \\
\text { Chem } \\
\text { Prop } \\
\end{array}$ & $\begin{array}{l}\text { RCSI } \\
\text { ACS } \\
\text { Prop } \\
\end{array}$ & $\begin{array}{c}\text { Post Burn } \\
\text { Mass }\end{array}$ & $\begin{array}{l}\text { Change } \\
\text { In Mass }\end{array}$ \\
\hline & & $(\mathrm{kg})$ & $(\mathrm{m} / \mathrm{s})$ & $(\mathrm{m} / \mathrm{s})$ & $(\mathrm{m} / \mathrm{s})$ & (s) & (s) & $(\mathrm{kg})$ & $(\mathrm{kg})$ & $(\mathrm{kg})$ & $(\mathrm{kg})$ & $(\mathrm{kg})$ \\
\hline 1 & Launch & 44756 & 0 & 0 & 0 & & & 0 & 0 & 0 & 44756 & 0 \\
\hline 2 & Null Tip off Rates & 44756 & 0 & 0 & 0 & & 330 & 0 & 0 & 1 & 44755 & -1 \\
\hline 3 & Correct Insertion Errors, target LGA & 44755 & 0 & 0 & 30 & & 330 & 0 & 0 & 413 & 44342 & -413 \\
\hline 4 & LGA 5 days after launch & 44342 & 0 & 0 & 0 & & & 0 & 0 & 0 & 44342 & 0 \\
\hline 5 & Vehicle Commissioning / Open arrays / test thrusters & 44342 & 0 & 0 & 0 & & & 0 & 0 & 0 & 44342 & 0 \\
\hline 6 & Transfer Into NRHO Using WSB (6months) & 44342 & 45 & 0 & 0 & 2600 & & 78 & 0 & 0 & 44263 & -78 \\
\hline 7 & 1 month of ACS Attitude Control & 44263 & 0 & 0 & 4 & & 330 & 0 & 0 & 50 & 44213 & -50 \\
\hline 8 & 5 months of SEP Attitude Control & 44213 & 17 & 0 & 0 & 2600 & & 30 & 0 & 0 & 44183 & -30 \\
\hline \multirow{2}{*}{9} & Dock To Gateway In NRHO & 44183 & 0 & 0 & 45 & & 330 & 0 & 0 & 610 & 43573 & -610 \\
\hline & Totals Before Resupply At Gateway & & 62 & 0 & 79 & & & 108 & 0 & 1074 & & \\
\hline 10 & Load required propellant & 43573 & 0 & 0 & 0 & & & 0 & 0 & 0 & 88253 & 44680 \\
\hline 11 & Load items that were offloaded from Hab & 88253 & 0 & 0 & 0 & & & 0 & 0 & 0 & 90149 & 1896 \\
\hline 12 & Load all logistics except $8.7 t$ that will be brought by Orion & 90149 & 0 & 0 & 0 & & & 0 & 0 & 0 & 104189 & 14040 \\
\hline 13 & Depart for LDHEO to meet up with crew via WSB & 104189 & 45 & 0 & 0 & 2600 & & 184 & 0 & 0 & 104006 & -184 \\
\hline 14 & Un-Phasing burn to eliminate Lunar resonance & 104006 & 0 & 20 & 0 & 351 & & 0 & 603 & 0 & 103403 & -603 \\
\hline 15 & LDHEO Maintenance $10 \mathrm{~m} / \mathrm{s} / \mathrm{rev}$ near apogee & 103403 & 100 & 0 & 0 & 2600 & & 405 & 0 & 0 & 102998 & -405 \\
\hline 16 & Crew Rendezvous With Orion and 13t Logistics Module & 102998 & 0 & 0 & 0 & & & 0 & 0 & 0 & 137416 & 34418 \\
\hline 17 & Transfer $8.7 t$ of logistics and spares from Logistics Module & 137416 & 0 & 0 & 0 & & & 0 & 0 & 0 & 137416 & 0 \\
\hline 18 & Separate Uncrewed Orion and Inert Logistics Module & 137416 & 0 & 0 & 0 & & & 0 & 0 & 0 & 112026 & -25390 \\
\hline 19 & Phasing for Departure, target LGA & 112026 & 0 & 20 & 0 & 351 & & 0 & 649 & 0 & 111377 & -649 \\
\hline 20 & 2 LGA to achieve $C 3=2 \mathrm{~km}^{\wedge} 2 / \mathrm{s}^{\wedge} 2$ & 111377 & 0 & 0 & 0 & & & 0 & 0 & 0 & 111377 & 0 \\
\hline 21 & Chemical Burn at Earth Escape & 111377 & 0 & 360 & 0 & 351 & & 0 & 11067 & 0 & 100310 & -11067 \\
\hline 22 & EP To Mars, DV 1 & 100310 & 2156 & 0 & 0 & 2600 & & 8134 & 0 & 0 & 92177 & -8134 \\
\hline 23 & EP To Mars, DV 2 & 92177 & 1040 & 0 & 0 & 2600 & & 3685 & 0 & 0 & 88492 & -3685 \\
\hline 24 & Attitude Control With SEP, Outbound & 88492 & 6 & 0 & 0 & 2600 & & 20 & 0 & 0 & 88472 & -20 \\
\hline 25 & Drop Outbound Used Consumables & 88472 & 0 & 0 & 0 & & & 0 & 0 & 0 & 86147 & -2325 \\
\hline 26 & MOI burn to $5 \mathrm{SOL}$ & 86147 & 0 & 138 & 0 & 351 & & 0 & 3381 & 0 & 82766 & -3381 \\
\hline 27 & Reorient For Mars Departure & 82766 & 11 & 0 & 0 & 2600 & & 37 & 0 & 0 & 82729 & -37 \\
\hline 28 & 5-Sol Parking Orbit Maintenance & 82729 & 20 & 0 & 0 & 2600 & & 65 & 0 & 0 & 82664 & -65 \\
\hline 29 & 300 Days of attitude Control with SEP & 82664 & 19 & 0 & 0 & 2600 & & 60 & 0 & 0 & 82604 & -60 \\
\hline 30 & Transfer $250 \mathrm{~kg}$ of samples from Martian Surface & 82604 & 0 & 0 & 0 & & & 0 & 0 & 0 & 82854 & 250 \\
\hline 31 & Drop Used Consumables From 300d Stay & 82854 & 0 & 0 & 0 & & & 0 & 0 & 0 & 77958 & -4896 \\
\hline 32 & TEI from 5-sol & 77958 & 0 & 220 & 0 & 351 & & 0 & 4825 & 0 & 73133 & -4825 \\
\hline 33 & Earth Return DV1 & 73133 & 2448 & 0 & 0 & 2600 & & 6695 & 0 & 0 & 66439 & -6695 \\
\hline 34 & Earth Return DV2 & 66439 & 609 & 0 & 0 & 2600 & & 1567 & 0 & 0 & 64872 & -1567 \\
\hline 35 & Attitude Control With SEP, Inbound & 64872 & 8 & 0 & 0 & 2600 & & 20 & 0 & 0 & 64852 & -20 \\
\hline 36 & Drop Inbound Used Consumables & 64852 & 0 & 0 & 0 & & & 0 & 0 & 0 & 62727 & -2125 \\
\hline 37 & 2 LGA, Achieve LDHEO & 62727 & 0 & 20 & 0 & 351 & & 0 & 363 & 0 & 62363 & -363 \\
\hline 38 & LDHEO Orbit Maintenance & 62363 & 30 & 0 & 0 & 2600 & & 73 & 0 & 0 & 62290 & -73 \\
\hline 39 & Orion arrives and docks with DST & 62290 & 0 & 0 & 0 & & & 0 & 0 & 0 & 83380 & 21090 \\
\hline 40 & LDHEO Orbit Maintenance & 83380 & 20 & 0 & 0 & 2600 & & 65 & 0 & 0 & 83315 & -65 \\
\hline 41 & Orion departs with crew to return safely to Earth & 83315 & 0 & 0 & 0 & & & 0 & 0 & 0 & 61897 & -21418 \\
\hline 42 & Target LGA & 61897 & 0 & 20 & 0 & 351 & & 0 & 359 & 0 & 61538 & -359 \\
\hline 43 & LDHEO to NRHO via WSB & 61538 & 45 & 0 & 0 & 2600 & & 109 & 0 & 0 & 61429 & -109 \\
\hline \multirow[t]{2}{*}{44} & ACS Prop For Potential Safe Modes & 61429 & 0 & 0 & 9 & & 330 & 0 & 0 & 180 & 61249 & -180 \\
\hline & Totals After Resupply At Gateway & & 6556 & 798 & 9 & & & 21118 & 21246 & 180 & & \\
\hline & Transfer required RCS propellant from commerical tanker & 61249 & 0 & 0 & 0 & & & 0 & 0 & 0 & 62194 & 945 \\
\hline \multirow{2}{*}{46} & Dock To Gateway & 62194 & 0 & 0 & 45 & & 330 & 0 & 0 & 859 & 61335 & -859 \\
\hline & Total & & 6619 & 798 & 88 & & & 21226 & 21246 & 1254 & & \\
\hline
\end{tabular}

This section will provide a more detailed explanation for the $\Delta \mathrm{Vs}$ captured in Table 2 and applied throughout the various phases of the mission. These $\Delta \mathrm{Vs}$ were used to derive the propellant masses for the chemical and EP systems.

\section{Launch through Docking with Gateway (Phases 1 to 9 in Table 2)}

The DST launches on the SLS with enough propellant to reach the NRHO and dock with Gateway. The launch includes a 23,813 kg inert Transport Module (the propulsion and power portion of the DST), a 19,760 kg inert Habitat mass, along with $1,074 \mathrm{~kg}$ usable RCS/ACS and $108 \mathrm{~kg}$ of usable xenon, for a total launch mass of 44,756 kg. The RCS/ACS system is used to null tip-off rates, correct insertion errors and target a LGA, as well as provide attitude control and perform the docking maneuver to Gateway in the NRHO. The EP system is assumed to perform the necessary $\Delta \mathrm{V}$ to transfer into the NRHO via the WSB following an LGA, as well as provide attitude control during the transfer. It is assumed that Gateway provides all required orbit maintenance and attitude control while DST is docked to it in the NRHO.

2. Refit DST with Propellant and Logistics in the NRHO (Phases 10 to 12 in Table 2)

The amount of usable propellant required to complete the remaining portion of the mission was calculated by applying the rocket equation to all remaining $\Delta \mathrm{Vs}$, ensuring that the vehicle inert mass was returned to Earth. The usable propellant includes $21,118 \mathrm{~kg}$ of xenon, $21,246 \mathrm{~kg}$ of main chemical propellant, and $180 \mathrm{~kg}$ of RCS/ACS propellant. Including margin, a total of $44,680 \mathrm{~kg}$ of propellant is loaded onto DST while in the NRHO, as seen on 
line 10. In addition to propellant, $14,040 \mathrm{~kg}$ of logistics, as well as $1,896 \mathrm{~kg}$ of items that were offloaded from the Habitat at launch are also loaded on DST, as seen on lines 11 and 12 in Table 2.

3. Depart NRHO, Rendezvous with Crew in LDHEO, Transfer Additional Logistics (Phases 13 to 17 in Table 2)

After refueling and outfitting, the DST then departs the NRHO to rendezvous with Orion in an LDHEO. Orion brings a 13,000 kg co-manifested logistics module and docks to the DST in the LDHEO. The crew transfer 8,700 kg of logistics from the logistics module to the DST.

\section{Earth Departure (Phases 18 to 21 in Table 2)}

With all required propellant and logistics loaded, and the crew onboard, the DST is ready to depart for Mars. The now un-crewed Orion vehicle separates from DST along with the empty logistics module. The DST performs phasing burns to target the 2 LGA sequence to increase the outgoing $C_{3}$ to a value of $2 \mathrm{~km}^{2} / \mathrm{s}^{2}$. The chemical system performs a TMI burn to further increase the departure energy following the LGA maneuvers.

For a detailed explanation of the heliocentric portion of the mission, the 300 day stay at Mars, and return to the NRHO (phases 22 to 44), see section A, baseline reference trajectory.

Once back in the NRHO, the DST docks to Gateway. Rather than carry all of the required propellant to perform this docking maneuver $(859 \mathrm{~kg}$ ) all the way to Mars and back, it was assumed that a commercial flight would bring up the required propellant, dock to DST and transfer it prior to DST docking with Gateway.

\section{Spacecraft and Mission Growth Approach}

The Compass Team utilizes the AIAA S-120-2006, "Standard Mass Properties Control for Space Systems," as the guideline for its mass growth calculations. To provide clarity, the mass terms and approach, which follow the AIAA guidelines and are utilized by the Compass team for this design are described below.

Basic mass is the bottoms-up estimate of component mass, as determined by the subsystem leads. This design assessment is the estimated, calculated, or measured (actual) mass, and includes an estimate for undefined design details like cables, multilayer insulation, and adhesives. Basic mass is subject to change as the design matures, therefore subsystem designers estimate this growth, called mass growth allowance (MGA). MGA is the predicted change to the basic mass of an item based on an assessment of its design maturity, fabrication status, and any in-scope design changes that may still occur. Propellant mass (including pressurant) is carried in the Basic Mass listing, but the growth approach is unique, as MGA is not applied to it. Margins on propellant are carried in the propellant calculation itself or in the $\Delta \mathrm{V}$ used to calculate the propellant required to fly a mission. When MGA is added to the basic mass, the resulting number is the predicted mass. Basic mass, MGA, and predicted mass are represented as separate columns on Table 3 and Table 4, with predicted mass shown in Table 7.

Estimated spacecraft dry mass is the total basic mass for the spacecraft element, without propellant. When propellant is included with the basic mass, this number becomes the estimated spacecraft wet mass, and includes propellant used, predicted boil-off, residuals, reserves, etc.

As previously mentioned, Compass follows AIAA S-120-2006, where the total growth is prescribed to be $30 \%$ of the Dry Mass of the entire spacecraft system. When $30 \%$ is applied to this design, the resulting number is represented in Table 3 and Table 4 as "Dry Mass Desired System Level Growth.". When the growth for each subsystem is compiled, an aggregate growth percentage can be determined, as a percentage of total estimated spacecraft dry mass. It is often necessary to carry additional growth beyond the aggregate MGA at the Spacecraft level, such that the total spacecraft system reaches the dry mass desired system level growth of $30 \%$. This additional growth is reflected in Table 3 and Table 4 as "Additional Growth (carried at system level), or "System Level Growth."

Finally, when the basic mass, MGA, and system level growth are summed together, including propellant, the result is the "Total Wet Mass with Growth" or "Total Mass." These terms and concept are captured graphically in Figure 4.

The mass and growth terms and approach as discussed, are applied to this design study, and the resulting numbers are illustrated in Table 3 for the Power and Propulsion Transport Element, and Table 4 for the Payload Element.

\section{DST Propulsion and Power Stage Subsystem Summaries}

Referred to as the baseline DST concept design, this concept assumed the use of a cryogenic chemical propulsion system and a near-term Hall thruster electric propulsion system. This design was an integrated single launch design, and the masses of the Transport module and the Payload (Habitat) are summarized on Tables 3 and 4 respectively. Rather than design them as two separate elements, the DST was designed as an integrated single spacecraft which included both the crew Habitat and the propulsion transport module. Everything not in the crew Habitat can be 
described as a power and propulsion transport module. In order to design this Transport module, assumptions were made as to systems available on the habitat and requirements from the Habitat that were levied on the DST propulsion and power transport module.

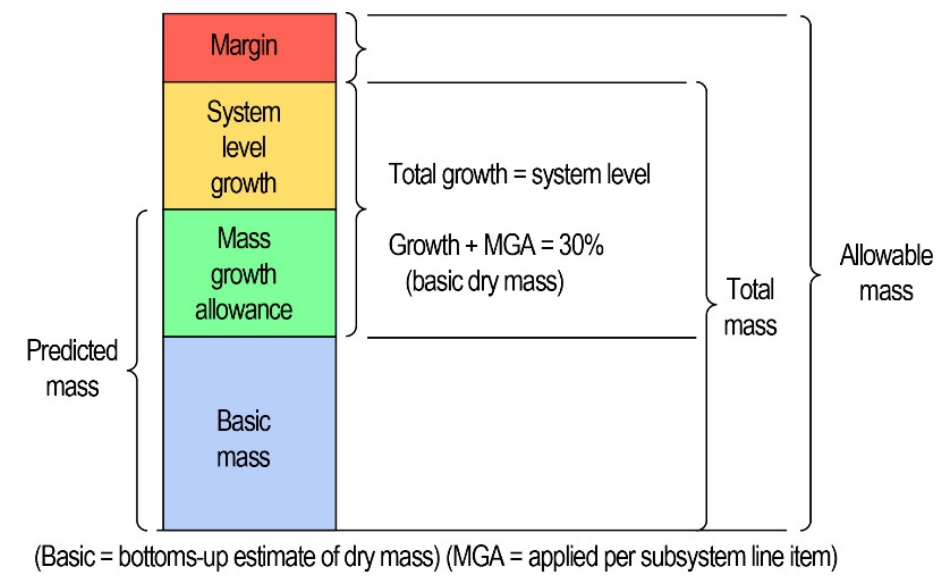

Figure 4: Graphical illustration of the definition of basic, predicted, total and allowable mass

Table 3: Baseline DST Propulsion and Power Stage Mass Summary

\begin{tabular}{|c|c|c|c|}
\hline \multicolumn{4}{|l|}{ Spacecraft MEL } \\
\hline Main Subsystems & Basic Mass (kg) & Growth (kg) & Predicted Mass (kg) \\
\hline Power and Propulsion Transport & 19633 & 2993 & 22627 \\
\hline Attitude Determination and Control & 44 & 1 & 45 \\
\hline Command \& Data Handling & 85 & 24 & 110 \\
\hline Communications and Tracking & 10 & 1 & 11 \\
\hline Electrical Power Subsystem & 4960 & 864 & 5824 \\
\hline Thermal Control (Non-Propellant) & 1713 & 308 & 2022 \\
\hline Propulsion (Chemical Hardware) & 2675 & 376 & 3051 \\
\hline Propellant (Chemical) & 1476 & & 1476 \\
\hline Propulsion (EP Hardware) & 3144 & 451 & 3595 \\
\hline Propellant (EP) & 137 & & 137 \\
\hline Structures and Mechanisms & 5389 & 967 & 6356 \\
\hline Estimated Transport Dry Mass & 18020 & 2993 & 21013 \\
\hline Estimated Transport Wet Mass & 19633 & 2993 & 22627 \\
\hline Dry Mass Desired System Level Growth & 18020 & 5406 & 23426 \\
\hline Additional Growth (carried at system level) & & 2413 & \\
\hline Total Wet Mass with Growth & 19633 & 5406 & 25039 \\
\hline
\end{tabular}

Table 4: Baseline DST Payload Mass Summary

\begin{tabular}{|c|c|c|c|}
\hline \multicolumn{4}{|l|}{ Spacecraft MEL } \\
\hline Main Subsystems & Basic Mass (kg) & Growth (kg) & Predicted Mass (kg) \\
\hline Payload & 19760 & $\mathbf{0}$ & 19760 \\
\hline Hab Module & 19631 & 0 & 19631 \\
\hline Attitude Determination and Control & 49 & 0 & 49 \\
\hline Electrical Power Subsystem & 80 & 0 & 80 \\
\hline Estimated Payload Dry Mass & 19760 & 0 & 19760 \\
\hline Estimated Payload Wet Mass & 19760 & 0 & 19760 \\
\hline Dry Mass Desired System Level Growth & 19760 & 0 & 19760 \\
\hline Additional Growth (carried at system level) & & 0 & \\
\hline Total Wet Mass with Growth & 19760 & 0 & 19760 \\
\hline
\end{tabular}

In this Compass design, the external components of which are shown in Figure 5, the main propulsion system was a hybrid configuration and consisted of both a chemical $\mathrm{LO}_{\mathrm{X}} / \mathrm{LCH}_{4}$ cryogenic system and a $13.3 \mathrm{~kW}$ Hall thruster electric propulsion system. These two systems were based on the $\mathrm{LO}_{\mathrm{X}} / \mathrm{LCH}_{4}$ systems that are currently being assumed 
as main propulsion system for the Mars ascent vehicle under study by NASA human Mars concept studies and the PPE which is planned as the first element of NASA's Gateway, respectively. For the Compass baseline concept, the primary chemical propulsion system consisted of four $1000 \mathrm{lbf} \mathrm{LO}_{\mathrm{X}} / \mathrm{LCH}_{4}$ thrusters for main chemical propulsion and forty-eight $100 \mathrm{lbf} \mathrm{GO}_{\mathrm{X}} / \mathrm{GCH}_{4}$ thrusters for Reaction Control System (RCS). The trajectory design required $\sim 15 \mathrm{t}$ of cryogenic $\mathrm{LO}_{X} / \mathrm{LCH}_{4}$. The main propulsion system's propellant was assumed to be actively cryocooled $(\sim 1000 \mathrm{~W}$ input) to maintain zero boiloff and was assumed to be designed to be refueled on-orbit. The primary SEP system consisted of two pallets of twelve $13.3 \mathrm{~kW}$ Hall thrusters each and twelve cylindrical xenon tanks carrying the $22 \mathrm{t}$ of xenon propellant required to perform the roundtrip trajectory. This xenon propellant is also assumed to be refueled on-orbit before each use and reuse of the DST.

The power system supplied $13.3 \mathrm{~kW}$ for each thruster, and individual PPUs (Power Processing Units) were included to provide high voltage $(600 \mathrm{~V})$ to the Hall thrusters. In addition to the EP system power, the arrays also supplied $29 \mathrm{~kW}$ of power to the Habitat. The design of the power system consisted of two $250 \mathrm{~kW}$ BOL/1 AU Mega ROSA arrays, running at $120 \mathrm{~V}$ from primary solar array. These arrays were common 27 - by 8-m ROSA panels using triple junction ZTJ cells and suspended away from the main vehicle structure on booms to avoid the crew vehicle and thrust plumes. The BOL solar array power for the baseline Case 1 (and for Case 2 as well) operating at $120 \mathrm{~V}$ was 485 $\mathrm{kW}$. The solar arrays were a total area of $1029.7 \mathrm{~m}^{2}$ and total mass of $1650 \mathrm{~kg}$.

For the purpose of this concept design, the Command and Data Handling (C\&DH) and communications systems primarily relied on the larger systems assumed to be present on the crew Habitat to provide far range communications and vehicle propulsion system and attitude system operations. The main computers on board the DST propulsion module would interface with Habitat and have a minimum of $100 \mathrm{~GB}$ data on board storage. For navigation while in the NRHO, before the crew meets the DST in the Orion and transfers to the DST, two redundant X-band systems for hybrid module operation which were separate from the Habitat were assumed on the DST propulsion module. The Habitat computers were assumed responsible for generating the trajectory for main propulsion and commanding the RCS for control.

The Thermal Control system consisted of roughly $119 \mathrm{~m}^{2}$ of deployed radiators capable of radiating $\sim 32,000$ Wth from the SEP, PMAD and module systems. It was assumed that the Habitat would have its own thermal systems and the propulsion and power module of the DST would not be responsible of thermal control of the Habitat.

The Guidance Navigation and Control (GN\&C) system consisted of RCS thrusters and, although not included in the baseline design, potentially CMGs. Star trackers were included to provide pointing knowledge.
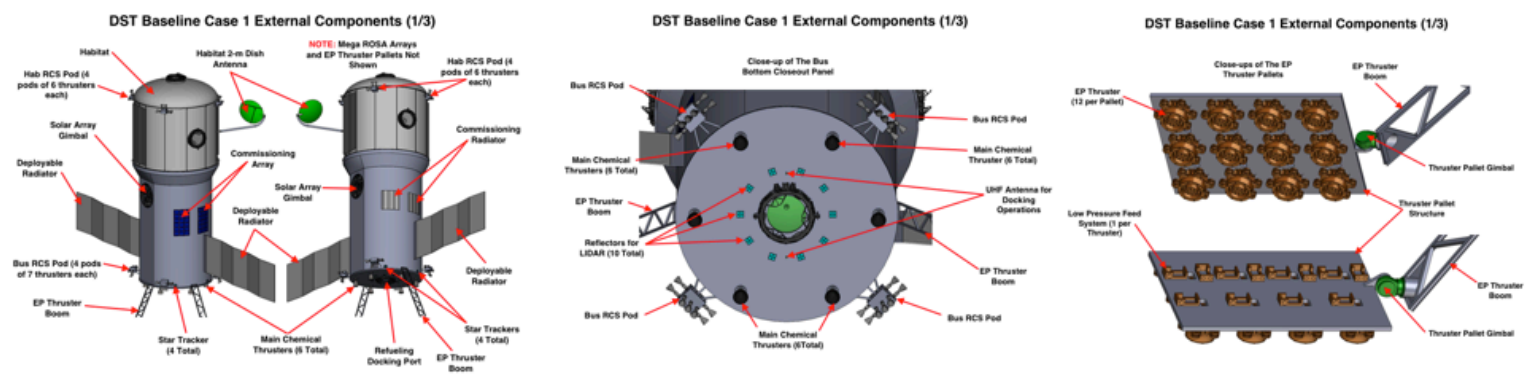

Figure 5: Three views of the DST Baseline Case identification of External Components

\section{Spacecraft Configuration}

The conceptual DST was designed to fit inside a single SLS $8.4 \mathrm{~m}$ fairing during launch. Figure 6 shows the notional DST concept design, consisting of the integrated crew Habitat (top) and power and propulsion Transport Module (bottom) as it would fit inside the SLS $8.4 \mathrm{~m}$ shroud. The booms for both the solar arrays and the thrusters are folded in order to stow both arrays against the main fuselage. Notional dimensions of the design are shown, and the configuration follows the envelope guidance in the SLS payload planners guide. [17]

Shortly after insertion on the TLI toward the moon, the NRHO, the DST deploys both solar arrays and thruster booms as shown in Figure 7. The purpose for separating the thruster pods from the vehicle with booms is to prevent the thruster plumes from impinging on the main vehicle and the solar arrays. Likewise, the solar array booms allow for both articulation of the arrays to track the Sun and to provide clearance to keep the arrays out of the thruster pod 
plumes. Notional dimensions of the deployed configuration are also shown in Figure 6 . When fully deployed, longest dimension across the solar arrays is $84.01 \mathrm{~m}$. The two solar array panels are each $39.09 \mathrm{~m}$ x $28.46 \mathrm{~m}$. The solar array booms offer $10.91 \mathrm{~m}$ distance between the DST power and propulsion module nad the solar array

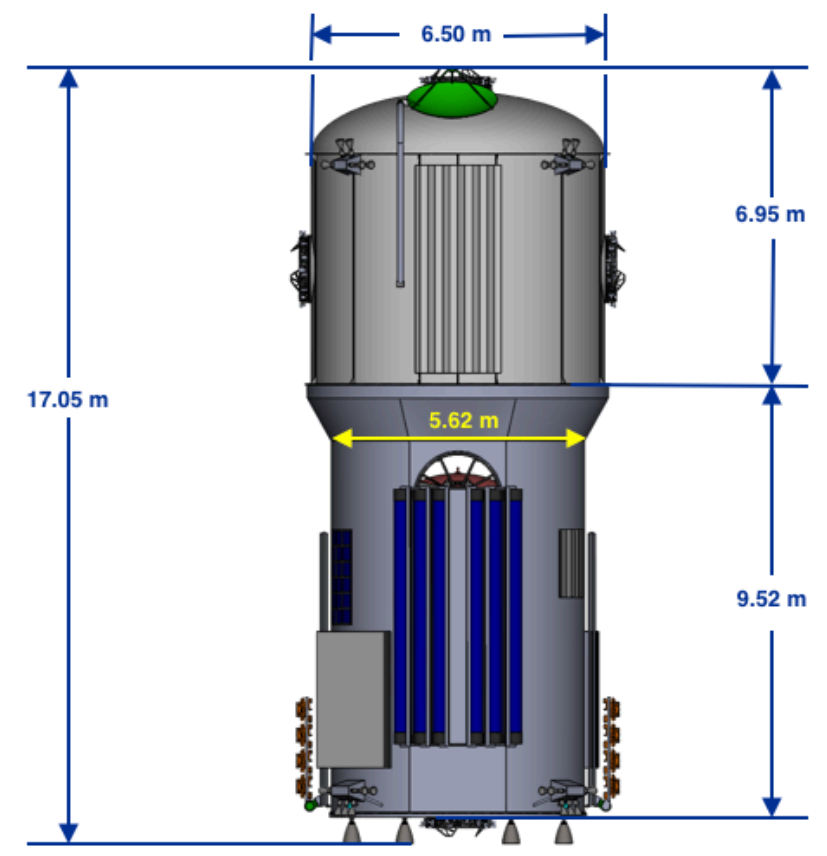

Figure 6: DST Stowed Configuration with Dimensions

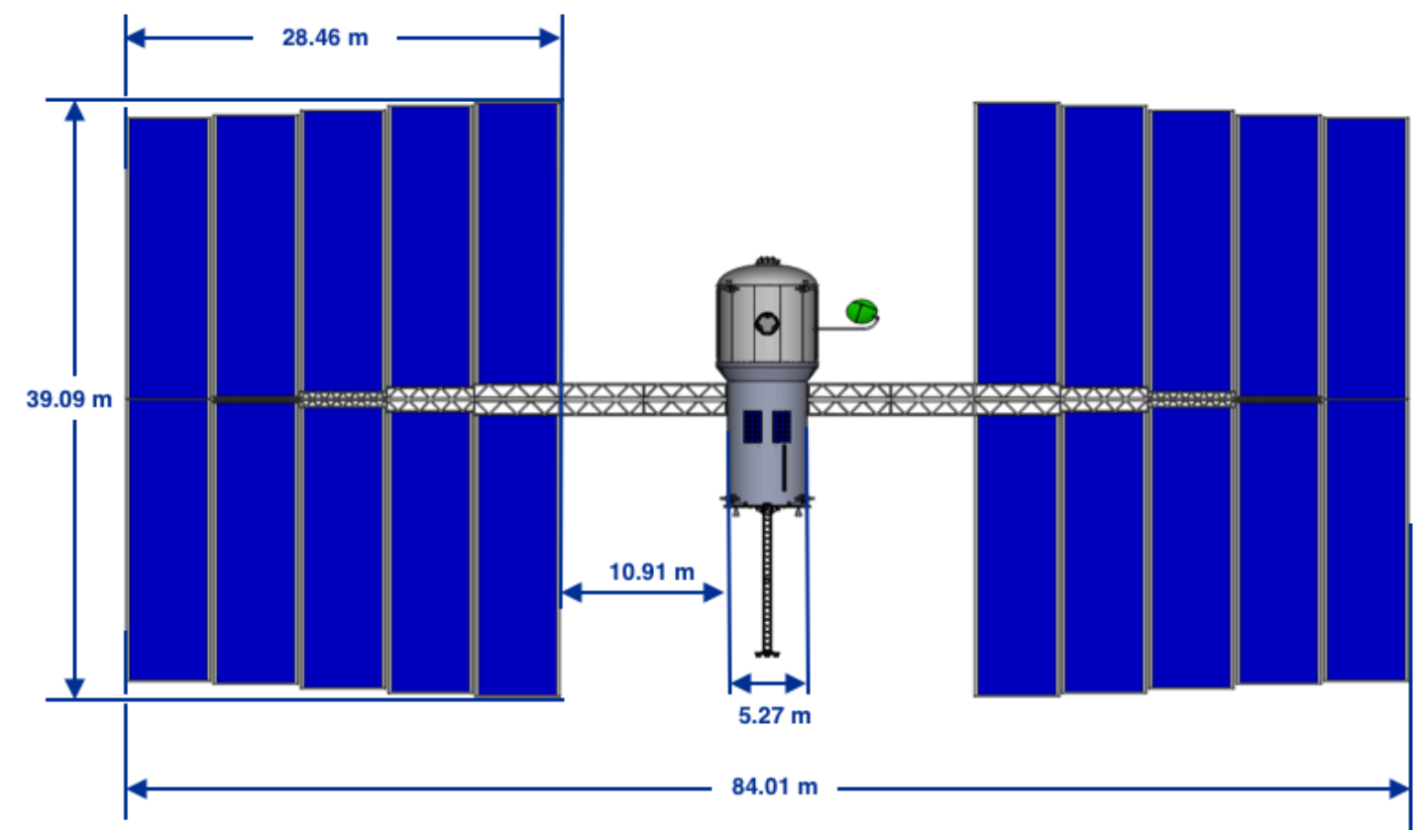

Figure 7: DST Deployed Configuration with dimensions

\section{VII.Trade Summary}

In additional to the single point design of the SEP/Chem hybrid vehicle, the Compass Team design study focused on technology trades in both the chemical and electric propulsion systems. Two different chemical propulsion technologies ( $\mathrm{LO}_{\mathrm{X}} / \mathrm{LCH}_{4}$ and storable $\mathrm{NTO} / \mathrm{MMH}$ systems) were traded to understand the impact on the vehicle design 
and corresponding trajectory. Utilizing these systems on the DST in addition to the landed assets could allow for cost and technology development savings in the overall Mars architecture. NASA's Mars architecture currently under study makes wide use of the performance gains of $\mathrm{LO}_{\mathrm{x}} / \mathrm{CH}_{4}$ systems. Additionally, two different electric propulsion thruster string systems (13.3 kW AEPS Hall Effect and future technology $50 \mathrm{~kW}$ Hall effect) were examined to understand the benefits to the mission for developing more efficient, higher power thruster strings. The $13.3 \mathrm{~kW}$ AEPS thruster string, also referred to as the HERMeS thruster [18], will be demonstrated on NASA's upcoming PPE which will provide propulsive capability for Gateway.

The baseline case performed by Compass for the MSC team and captured in this paper assumed the use of a $\mathrm{LO}_{\mathrm{X}} / \mathrm{LCH}_{4}$ chemical propulsion system and the AEPS $13.3 \mathrm{~kW}$ EP thruster strings. The driving assumption behind this case (Case 1 in Table 5) was to keep all subsystems as close to near term technology where possible, while leveraging technologies being utilized by other human exploration vehicles. For example, the system voltage was assumed to be $120 \mathrm{~V}$ and the solar array design assumed $29.5 \%$ efficient ZTJ cells. The EP system relied on the 13 $\mathrm{kW}$ AEPS contract string operating only at their current $600 \mathrm{~V}$ set point. Being unable to operate at a lower voltage reduced the SEP thrust level for the outbound leg of the trajectory leading to the need for a chemical TMI burn requiring $\sim 10 \mathrm{t}$ of chemical propellant. In Case 2 the chemical system was changed from the cryo-propellant system assumed in Case 1 to a more near-term technology storable system using NTO/MMH as the propellants. In Case 3, the cryo-propulsion system from Case 1 was paired with a proposed future high-power Hall Effect Rocket with Magnetic Shielding (HERMeS') $50 \mathrm{~kW}$ EP thruster strings and the solar array harness was run at $300 \mathrm{~V}$ using the same ZTJ cells as cases 1 and 2. HERMeS' is the next iteration of the AEPS thrusters being developed for in-space EP system applications. This development was based on the identified need for SEP thruster systems capable of operating at Isp in the 2000s range at full power. The HERMeS' thruster will be designed to operate near 50kW at the lower 300V/2000s setpoint (necessitating a $\sim 150 \mathrm{amp}$ cathode compared to AEPS 20-amp cathode). The PPE will demonstrate and characterize the high-power SEP system utilizing the AEPS thrusters. This on-orbit data from PPE combined with the HERMeS' ground-testing will lead to high-confidence in the HERMeS' thruster string.

Table 5: Propulsion Trades Case Description Summary

\begin{tabular}{|c|c|c|c|}
\hline Subsystem details per Trade Case & $\begin{array}{c}\text { Case 1: (Baseline) } \\
\text { Near Term SEP + } \\
\text { LO }_{\mathbf{X}} / \mathrm{LCH}_{4} \\
\end{array}$ & $\begin{array}{c}\text { Case 2: } \\
\text { Near Term SEP + } \\
\text { Storable Chem }\end{array}$ & $\begin{array}{c}\text { Case 3: } \\
50 \mathrm{~kW} \text { EP Thruster } \\
\text { Strings }+\mathrm{LO}_{\mathrm{X}} / \mathrm{LCH}_{4}\end{array}$ \\
\hline Electric Propulsion system & $\begin{array}{c}13.3 \mathrm{~kW} \text { Hall thruster } \\
\text { strings, } 120 \mathrm{~V} \text { PPU }\end{array}$ & $\begin{array}{c}13.3 \mathrm{~kW} \text { Hall thruster } \\
\text { strings, } 120 \mathrm{~V} \text { PPU }\end{array}$ & $\begin{array}{c}50 \mathrm{~kW} \mathrm{EP} \text { strings, } 300 \mathrm{~V} \\
\text { PPU }\end{array}$ \\
\hline Chemical Propulsion system & Cryo $\mathrm{LO}_{\mathrm{X}} / \mathrm{LCH}_{4}$ & $\begin{array}{c}\text { Storable Chemical } \\
\text { NTO/MMH }\end{array}$ & Cryo $\mathrm{LO}_{\mathrm{X}} / \mathrm{LCH}_{4}$ \\
\hline Communications & UHF use Habitat comm & UHF use Habitat comm & UHF use Habitat comm \\
\hline Launch Vehicle & SLS, $8.4 \mathrm{~m}$ fairing & SLS, $8.4 \mathrm{~m}$ fairing & SLS, 8.4 m fairing \\
\hline Power (SAS) & $485 \mathrm{~kW}$ (BOL $1 \mathrm{AU})$ & 485 kW (BOL 1 AU) & $509 \mathrm{~kW}$ (BOL $1 \mathrm{AU})$ \\
\hline Solar Array cell technology and voltage & $120 \mathrm{~V}, \mathrm{ZTJ}$ cells & $120 \mathrm{~V}, \mathrm{ZTJ}$ cells & $300 \mathrm{~V}, \mathrm{ZTJ}$ cells \\
\hline
\end{tabular}

\section{A. Propulsion System Trade: Effects on the SEP-Hybrid Trajectory}

Three separate DST concept designs were completed to evaluate technology trades in the chemical and electric propulsion systems including two different EP thrusters and two different main and RCS propellant combinations.

As discussed, two EP thrusters were evaluated: the $13.3 \mathrm{~kW}$ Advanced Electric Propulsion System (AEPS) Contract Hall thruster strings and the NASA proposed $50 \mathrm{~kW}$ HERMeS' thruster strings. For cases using the AEPS thruster strings, 24 total thrusters were placed on the DST Transport module resulting in a maximum power of approximately $319 \mathrm{~kW}$ usable by the thrusters. For cases using the HERMeS' thrusters, eight total thrusters were placed on the SEP-Chem bus resulting in a maximum power of approximately $400 \mathrm{~kW}$ usable by the thrusters.

The trajectory analysis used the $13.3 \mathrm{~kW}$ AEPS contractual performance requirements $600 \mathrm{~V}(13.3 \mathrm{~kW}$ at $600 \mathrm{~V})$ performance curve for SEP propulsion system. [19] This operation point corresponds to a specific impulse of approximately $2666 \mathrm{~s}$ at $13.3 \mathrm{~kW}$. Optimal operation of an SEP system of this type for the SEP-Hybrid mission is higher thrust $(300 \mathrm{~V})$ during the outbound leg and higher Isp $(600 \mathrm{~V})$ during the return leg. However, because the AEPS can only operate at a single voltage setting, $600 \mathrm{~V}$, insufficient thrust is produced to achieve the acceleration necessary to eliminate a TMI burn.

As previously mentioned, HERMeS' is a proposed next iteration of the AEPS thrusters being developed for PPE and would be a scaled-up version of the HERMeS/AEPS thruster with a new PPU capable of providing full power operation at two voltage setpoints, 300 and $600 \mathrm{~V}$, respectively. This corresponds to a specific impulse at $50 \mathrm{~kW}$ of 
approximately 2000 and 2600 s, respectively. The increased thruster string power also reduced the required number of thruster strings from twenty-four down to eight, thereby reducing the overall complexity of the EP system.

A trade to evaluate cryogenic versus storable propellant storage resulted in two different chemical propellant combinations: $\mathrm{LO}_{\mathrm{X}} / \mathrm{LCH}_{4}$ Main Propulsion with supercritical bipropellant RCS, and monomethyl hydrazine and nitrogen tetroxide (MON-3). A summary of the Compass point designs is given in Table 6. In this table, Case 1 represents the trajectory used for the baseline DST design outlined in this paper. Further details on the impacts of the propulsion system trades on the SEP-Hybrid trajectory can be found in [6].

A Summary of the total masses and subsystem masses of the three main propulsion system trades can be found in Table 7. The masses shown in this table are predicted mass, whose definition was previously described.

Table 6: Summary of Interplanetary Trajectories for Compass Technology Trade Point Designs

\begin{tabular}{|c|c|c|c|}
\hline Performance Highlights & $\begin{array}{c}\text { Case 1: (Baseline) } \\
\text { Near Term } \\
\text { SEP+LOx } / \mathrm{LCH}_{4}\end{array}$ & $\begin{array}{c}\text { Case } 2: \\
\text { Near Term } \\
\text { SEP+Storable } \\
\text { Chem }\end{array}$ & $\begin{array}{c}\text { Case 3: } \\
50 \mathrm{~kW} \text { EP Thruster } \\
\text { Strings }+\mathrm{LO}_{\mathrm{X}} / \mathrm{LCH}_{4}\end{array}$ \\
\hline EP Thruster Power & $13.3 \mathrm{~kW}$ & $13.3 \mathrm{~kW}$ & $50 \mathrm{~kW}$ \\
\hline EP Thruster Curve(s) & AEPS Contract & AEPS Contract & HERMeS' \\
\hline Number of EP Thruster Strings & 24 & 24 & 8 \\
\hline EP system power $(\mathrm{kW})$ & 319 & 319 & 400 \\
\hline Total Interplanetary TOF (d) & 1036 & 1035 & 1035 \\
\hline Total SEP DV $(\mathrm{m} / \mathrm{s})$ & 6264 & 6317.1 & 6557.8 \\
\hline Outbound SEP DV (m/s) & 3196 & 3221.0 & 3485.2 \\
\hline Re-orientation SEP DV $(\mathrm{m} / \mathrm{s})$ & 11.4 & 11.2 & 9.5 \\
\hline Inbound SEP DV $(\mathrm{m} / \mathrm{s})$ & 3056.4 & 3084.9 & 3063.1 \\
\hline Total Chem DV (m/s) & 717.9 & 704.7 & 359.9 \\
\hline TMI DV $(\mathrm{m} / \mathrm{s})$ & 360.2 & 353.6 & 0.0 \\
\hline MOI DV (m/s) & 137.8 & 136.5 & 139.3 \\
\hline TEI DV $(\mathrm{m} / \mathrm{s})$ & 219.9 & 214.6 & 220.6 \\
\hline Total Xenon Propellant (t) & 20.2 & 20.2 & 24.9 \\
\hline Total Chemical Propellant (t) & 19.4 & 21.1 & 8.0 \\
\hline Mass at Earth Escape (t) & 111.9 & 112.7 & 103.3 \\
\hline Mass at Earth Return (t) & 63 & 62 & 61 \\
\hline Acceleration following TMI $\left(\mathrm{km} / \mathrm{s}^{2}\right)$ & $1.318 \times 10^{-7}$ & $1.322 \times 10^{-7}$ & $1.894 \times 10^{-7}$ \\
\hline
\end{tabular}

Table 7: Propulsion Trade DST Predicted Mass Comparison at Launch

\begin{tabular}{|c|c|c|c|}
\hline System Description & $\begin{array}{l}\text { Case 1: (Baseline) } \\
\text { Near Term SEP+ } \\
\text { LO } / \mathrm{LCH}_{4} \\
\\
\text { Mass }(\mathrm{kg})\end{array}$ & $\begin{array}{c}\text { Case 2: } \\
\text { Near Term } \\
\text { SEP+Storable } \\
\text { Chem } \\
\text { Mass }(\mathrm{kg})\end{array}$ & $\begin{array}{c}\text { Case 3: } \\
50 \text { kW EP Thruster } \\
\text { Strings }+ \\
\mathrm{LOx} / \mathrm{LCH}_{4} \\
\text { Mass }(\mathrm{kg})\end{array}$ \\
\hline DST Total Mass & 42395 & 41192 & 40511 \\
\hline Power and Propulsion Transport & 22627 & 21423 & 20742 \\
\hline Science & 45 & 45 & 45 \\
\hline Attitude Determination and Control & 110 & 110 & 110 \\
\hline Command and Data Handling & 11 & 11 & 11 \\
\hline Communications and Tracking & 5824 & 5754 & 5286 \\
\hline Electrical Power System & 2022 & 1794 & 1758 \\
\hline Thermal Control (non-Propellant) & 3051 & 2496 & 2664 \\
\hline Propulsion (Chemical Hardware) & 1476 & 1353 & 1420 \\
\hline Propellant (Chemical) & 3595 & 3595 & 3831 \\
\hline Propulsion (EP Hardware) & 137 & 136 & 133 \\
\hline Propellant (EP) & 6356 & 6131 & 5484 \\
\hline Structures and Mechanisms & 19769 & 19769 & 19769 \\
\hline Payload & 19631 & 19631 & 19631 \\
\hline Hab Module & 49 & 49 & 49 \\
\hline Attitude Determination and Control & 89 & 89 & 89 \\
\hline Electrical Power System & 44799 & 43671 & 42705 \\
\hline Total Mass with System Growth & 42395 & 41192 & 40511 \\
\hline
\end{tabular}




\section{VIII.Conclusion}

The Compass baseline DST design Case 1, which assumed near term SEP and advanced $\mathrm{LO}_{\mathrm{X}} / \mathrm{LCH}_{4}$ successfully fit on a single SLS launch (104 kg of launch margin) but had a slightly larger departure wet mass (112 mt) compared to Case 2 and Case 3. This design stretched the bus dimensions to allow for single format ROSA elements. While the AEPS thruster is capable of operating at a lower Isp in the range of $2000 \mathrm{~s}$, it has to be run at half power ( $6 \mathrm{~kW}$, limited by 20-A cathode) in order to do so. This would necessitate the vehicle be configured with 48 thruster strings to use the available power and provide the desired thrust to perform the Earth departure portion of the low thrust transfer.

The second design case, Case 2, which included the use of the same near-term SEP as Case 1 but utilized Orion's storable chemical propellant propulsion systems (thrusters, tanks, etc.) instead of the lower TRL LOX $/ \mathrm{LCH}_{4}$ systems, allowed for even more dry mass launch margin. Because both the EP and the Chemical propulsion systems apply near term technology, the overall design has less technology development/risk. The current Mars mission CONOPS proposed that DST would be launched earlier than the other landed elements. This design results in an overall shorter vehicle by $\sim 2 \mathrm{~m}$. Because the storable propulsion system is less efficient (lower Isp) than $\mathrm{LO}_{\mathrm{X}} / \mathrm{LCH}_{4}$, this design slightly increases the refuel propellant mass $(1.7 \mathrm{t})$ required per launch.

The last case examined, Case 3, replaced the near-term SEP system with theoretical advanced SEP ( $50 \mathrm{~kW}$ strings) and $300 \mathrm{~V}$ arrays and retained the advanced $\mathrm{LO}_{\mathrm{X}} / \mathrm{LCH}_{4}$ system of the baseline Case 1 . Because this was a case assuming future technology developments, the solar arrays were assumed to run at a high voltage of $300 \mathrm{~V}$ but still using ZTJ cells. The arrays were run unregulated but capped at a max voltage to simplify the PPU design. This higher voltage resulted in a lower total solar array system mass for the same solar array areas $\left(1029.7 \mathrm{~m}^{2}\right)$ than Cases 1 and $2(1532 \mathrm{~kg}$ instead of $1650 \mathrm{~kg})$. Using the higher power SEP system eliminated the need for a chemical departure burn and therefore reduced the total round-trip mission propellant requirements by $>10 \mathrm{t}$ of chemical propellant. By using a thruster and PPU capable of $2000 \mathrm{~s}$ operation at $50 \mathrm{~kW}(\sim 150$ A cathode), the more efficient EP system was able to perform more of the Earth departure $\Delta \mathrm{V}$. Using fewer thruster strings and associated PPUs on the booms reduced the complexity of the thruster system design. The reduction in chemical propellant required to perform the mission, and subsequent reduction in tank size, shortened the concept vehicle by about $2 \mathrm{~m}$.

\section{IX.Forward Work}

As NASA's Mars teams continue to develop the architecture concepts for human missions to Mars, the Compass team will continue to update these design studies. Going forward, the team plans to update and fully document the concept design presented in this paper, once the assumptions used here are updated in the current design analysis cycles. For example, concept design work is still ongoing for the pressurized Habitat as well as determination of supplies and equations to guide consumables as a function of crew and crew trip time. Using these new payloads, the Compass team will continue these vehicle concept designs to identify technology performance to determine the best mix of SEP power level, associated Isp and chemical propellant loads. In addition to the combination of SEP and Chemical propulsion technology options examined in this paper, future analysis will evaluate the combination of storable propellants and number of high power, high thrust EP thrusters.

\section{Acknowledgments}

The authors wish to thank the outstanding men and women of the Compass team for their dedication to performing the many design studies involved in completing the various trades presented in this paper. Thank you to Compass' summer intern artist in residence, Alex Pawlusik, for bringing our concept designs to life. Special thanks to Dan Herman and his talented electric thruster experts for providing the estimated performance curves of the current AEPS and future higher power hall thrusters. Thank you to John Connolly, the lead of the Mars Study Team, for his guidance and support in steering the requirements for the human Mars mission concepts. And lastly, thank you to our project management, Dr. Michael Barrett, and line management, Josh Freeh and Derrick Cheston, for their support as we try to devise new and interesting solutions to future human Mars transportation options. 


\section{References}

[1] Connolly, John, Deep Space Transport and Mars Mission Architecture (Presentation), Oct. 17. 2017, https://nvite.jsc.nasa.gov/presentations/b2/D1_Mars_Connolly.pdf.

[2] Mercer, C.R., Oleson, S.R., and Drake, B.G., "A Combined Solar Electric and Storable Chemical Propulsion Vehicle for Piloted Mars Missions," SPACE 2013 Conference and Exposition, AIAA 2013-5492, San Diego, CA, 2016. See also NASA/TM-2014-218093, 2014.

[3] Drake, B.G. (ed.), “NASA’s Decadal Planning Team Mars Mission Analysis Summary,” NASA/TM-2007-214761, JSC63725, 2007.

[4] Percy, T.K., McGuire, M., and Polsgrove, T., "In-Space Transportation for NASA's Evolvable Mars Campaign," AIAA Space and Astronautics Forum and Exposition (AIAA SPACE 2015), AIAA 2015-4519, Pasadena, CA, 2015.

[5] Burke, Laura M., Martini, Michael C. and Oleson, Steven R., "A High Power Solar Electric Propulsion - Chemical Mission for Human Exploration of Mars," 50th AIAA/ASME/SAE/ASEE Joint Propulsion Conference; 28-30 Jul. 2014; GRC-EDAA-TN16239, Cleveland, OH.

[6] Gefert, L.P., Hack, K.J., "Low-Thrust Control Law Development for Transfer from Low Earth Orbits to High Energy Elliptical Parking Orbits," AAS/AIAA Astrodynamics Specialist Conference, AAS 99-410, 16-19 AUGUST 1999, Girdwood, Alaska.

[7] Freeh, J.E., Burke, L.M., Sjauw, W.K., McGuire, M.L., and Smith, B.K., "Comparison of Solar Electric and Chemical Propulsion Missions," 66th International Astronautical Congress (IAC 2015), IAC-15-D1.4.312-16, Jerusalem; Israel, 2015.

[8] Gefert, L.P., Hack, K.J., Kerslake T.W., "Options for the Human Exploration of Mars using Solar Electric Propulsion," STAIF Conference, Alberquerque, 1999.

[9] Burke, L.M., Oleson, S.R., Newman, J.M., and McGuire M.L., "Impact of Propulsion System Technology Trades on the Hybrid Solar Electric-Chemical Propulsion Deep Space Transport (DST) Vehicle Crewed Mission to Mars," pre-publication NASA TM 2018.

[10] Borowski, S.K., McCurdy, D.R., and Packard, T.W., "Nuclear Thermal Propulsion (NTP): A Proven, Growth Technology for Fast Transit Human Missions to Mars," Space 2013 Conference and Exposition, AIAA 2013-5354, 10-12 Sep. 2013; San Diego, CA, 2013. See also NASA/TM-2014-218104, 2014.

[11] Drake, B.G., Hoffman, S.J., and Beaty, D.W., "Human Exploration of Mars Design Reference Architecture 5.0," 2010 IEEE Aerospace Conference; IEEEAC paper 1205-13, Big Sky, MT; 2010.

[12] Drake, B.G. (ed.). "Human Exploration of Mars Design Reference Architecture 5.0, Addendum," NASA/SP-2009-566ADD.

[13] Hambleton, K. "Deep Space Gateway to Open Opportunities for Distant Destinations.” NASA. NASA, 28 Mar. 2017.

Web. 25 May 2017. https://www.nasa.gov/feature/deep-space-gateway-to-open-opportunities-for-distant-destinations.

[14] Williams, Jacob, Lee, David E., Whitley, Ryan J., Bokelmann, Kevin A., Davis, Diane C., Berry, Christopher F.

"Targeting Cislunar Near Rectilinear Halo Orbits for Human Space Exploration." 27th AAS/AIAA Space Flight Mechanics Meeting, AAS 17-267, 5-9 Feb. 2017; San Antonio, TX.

[15] C. Ocampo and J. Senent, "The Design and Development of COPERNICUS: A Comprehensive Trajectory Design and Opti-mization System," Paper IAC-06-C1.4.04, Oct. 2006.

[16] J. Williams, "Copernicus Trajectory Design and Optimization System,” NASA. NASA, 3 Nov. 2016. Web. 11 Jan.

2017. https://www.nasa.gov/centers/johnson/copernicus/index.html.

[17] “Space Launch System (SLS) Mission Planner's Guide,” Apr 12, 2017.

https://ntrs.nasa.gov/archive/nasa/casi.ntrs.nasa.gov/20170005323.pdf.

[18] Huang, Wensheng, Williams, George J., Peterson, Peter Y., Kamhawi, Hani, Gilland, James H., and Herman, Daniel A, "Plasma Plume Characterization of the HERMeS During a 1722-hr Wear Test Campaign," 35th International Electric Propulsion Conference (IEPC), NASA/TM-2017-219726, IEPC-2017-307, 8-12 Oct. 2017, Atlanta, GA.

[19] Stanley, S., Allen, M., Goodfellow, K., Chew, G., Rapetti, R., Tofil, T., Herman, D., Jackson, J., and Myers, R., "Development of a $13 \mathrm{~kW}$ Hall Thruster Propulsion System Performance Model for AEPS," 53rd AIAA/SAE/ASEE Joint Propulsion Conference, AIAA 2017-4726, Atlanta, GA, 2017. 